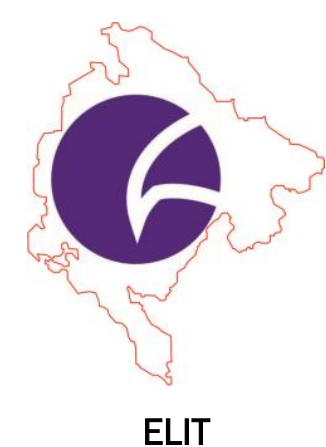

Economic Laboratory Transition Research Podgorica

\section{Montenegrin Journal of Economics}

Kozlovskyi, S., Bilenko, D., Ivanyuta, N., Tomchuk, O., Prykaziuk, N., Lobova, O. (2021),

"Comparative Assessment of the Different Cryptocurrencies Investment Efficiency on the Different Time Periods",

Montenegrin Journal of Economics, Vol. 17, No. 4, pp. 189-198.

\title{
Comparative Assessment of the Different Cryptocurrencies Investment Efficiency on the Different Time Periods
}

\author{
SERHII KOZLOVSKYI ${ }^{1}$, DARIA BILENKO ${ }^{2}$, NATALYA IVANYUTA ${ }^{3}$, \\ OLESIA TOMCHUK ${ }^{4}$, NATALIIA PRYKAZIUK ${ }^{5}$ and OKSANA LOBOVA 6
}

1 Professor, Vasyl' Stus Donetsk National University, Department of Entrepreneurship, Corporate and Spatial Economics, Vinnytsia, Ukraine, e-mail: s.kozlovskyy@donnu.edu.ua

2 Associate Professor, University of State Fiscal Service of Ukraine, Department of Finance named after L.I. Tarangul, Irpin, Ukraine, e-mail: belenkodaria1@gmail.com

3 Professor, Donetsk Law Institute of the Ministry of Internal Affairs of Ukraine, Department of Civil, Labour and Social Security Law, Mariupol, Ukraine, e-mail: natalaivanuta9@gmail.com

${ }^{4}$ Associate Professor, Vasyl' Stus Donetsk National University, Department of Management and Behavioral Economics, Vinnytsia, Ukraine, e-mail: o.tomchuk@donnu.edu.ua

5 Professor, Taras Shevchenko National University of Kyiv, Department of Insurance, Banking and Risk Management, Kyiv, Ukraine, e-mail: pnvuniv15@ukr.net

${ }^{6}$ Associate Professor, Taras Shevchenko National University of Kyiv, Department of Insurance, Banking and Risk Management, Kyiv, Ukraine, e-mail: lobova.ksu@gmail.com

\section{ARTICLE INFO}

Received January 21, 2021

Revised from March 02, 2021

Accepted april 12, 2021

Available online December 15, 2021

JEL classification: C25, E44, F37, 016

DOI: 10.14254/1800-5845/2021.17-4.17

Keywords:

Cryptocurrency, investment efficiency, investment horizon, regression data analysis.

\begin{abstract}
Cryptocurrency has appeared recently but become important part of the global financial sector. Some experts predict that cryptocurrency has changed the world forever because of its utility to transfer payments across borders with little cost or delay. Cryptocurrencies are traded with no broker and tracked on digital ledgers. Dramatic changes in the value of the cryptocurrency attract the investors' attention. Some of the have a one-day trading strategy, other investors construct crypto portfolio for a long time periods. The object of this study is value of Bitcoin, Ethereum, and Litecoin on short time periods and long time periods. The subject of the study is the statistical analysis methods to assess the different cryptocurrencies investment efficiency on the different time periods. The aim of the study is to find out what cryptocurrency strategy is better to use for investors. The analysis is carried out on randomly generated periods for 8 samples cryptocurrencies value. The result of the study allows to state that investor does not need to construct crypto portfolio based on its profitability. An effective strategy is to invest money for long time periods in any cryptocurrencies whose utilities meet the investor's requirements.
\end{abstract}

\section{INTRODUCTION}

Cryptocurrency is a type of currency that is digital and decentralized (Popper, 2016, Limba et al, 2020). According to PWC definition cryptocurrency is a medium of exchange, created and stored elec- 
tronically in the blockchain, using encryption techniques to control the creation of monetary units and to verify the transfer of funds. This digital money can be used to buy and sell things (Report by PWC, 2018). Cryptocurrency has its specific features such as it has no intrinsic value, it has no physical form, and its supply is not determined by a central bank. It means that cryptocurrency is not redeemable for another commodity, such as gold, exists only in the network that is completely decentralized (Goodman, 2019).

The original cryptocurrency is Bitcoin. Bitcoin is exactly the currency the unknown Satoshi Nakamoto created in 2009. Initially, thanks to Bitcoin it has become possible to reduce transaction fees compared traditional online payments tools (Derousseau, 2019). All the cryptocurrencies other than Bitcoin is named an Altcoin (Goodman, 2019). For today there are a plenty of different cryptocurrencies exist. The first ten cryptocurrencies with the highest market cap put together about $90 \%$ of the total cryptocurrency market value (Statista, 2021). The list of them is shown on the figure 1.

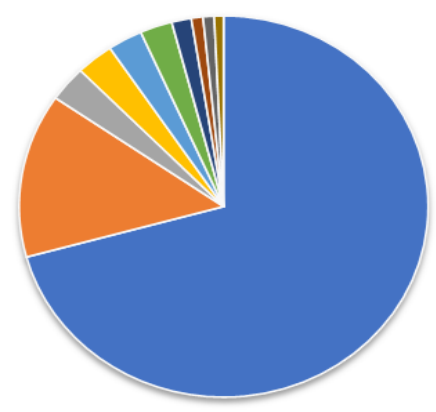

$$
\begin{aligned}
& \text { - Bitcoin } \\
& \text { - Ethereum } \\
& \text { - Cardano } \\
& \text { - Binance Coin } \\
& \text { - Tether } \\
& \text { - Polkadot } \\
& \text { - XRP } \\
& \text { - Chainlink }
\end{aligned}
$$

Figure 1. Market share of top 10 cryptocurrency for all period of their existing

Source: compiled by the authors based on Statista, 2021

The largest market share is occupied by Bitcoin, it is about $60 \%$. The market share of Ethereum is 12\%. The other cryptocurrencies have from 0,7\% to 3\% market share, their market cap is from 10 to 40 million dollars. In 2021 Bitcoin had the biggest market capitalization of more than one billion dollars. In January 2021 value of Bitcoin was 30000 dollars and in February it increased to 50000 dollars. For year it made a $400 \%$ increase in value. The global blockchain market is predicted at 23 billion dollars by 2023 (Bitcoin in Numbers by BlockSocial, 2021).

On the one hand, the ability of cryptocurrency to grow its value rapidly catches the eye of many investors. The vast majority of cryptocurrency investors are involved in day trading that means for them holding an asset until its value changes (Bryant, 2020). Such trading does not have need of proper analytical and technical skills. On the other hand, investing in cryptocurrency is not taken seriously by many large investors, because cryptocurrency do not fit the mold of traditional stock or bond (Hussain et al., 2020). So it is not understandable how to assess cryptocurrency investment efficiency. Further development of cryptocurrency market requires not only intuitive but research tools to assess the different cryptocurrencies investment efficiency on the both short time period and long time period.

\section{LITERATURE REVIEW}

Since cryptocurrency has become a very popular investment destination, many different publications have appeared both overview information for beginners and scientific predictions. The largest number of publications are devoted to the question of which cryptocurrency is better to invest in.

Investors trade through an automatic trading platform which allows deciphering the signals emitted by the cryptocurrencies. As a rule, the determination of the best cryptocurrencies for investment is made on the statistical data analysis that are updated in real time based on the results of trading on the trading platform and cryptocurrency exchange. 
One of the most popular website specializing in Bitcoin and digital currencies is CoinDesk. Since 2014 , an analytical overview of key cryptocurrency trends, challenges, and opportunities can be found on the website (CoinDesk Research report (2021).

Business magazine Forbes (Forbes Advisor, 2021) reviewed the top 10 cryptocurrency based on their market capitalization, or the total value of all of the coins currently in circulation. To determine rankings of cryptocurrency exchanges the importance of the different types of cryptocurrency for investors are taken into account. Making review researchers note that cryptocurrencies are speculative investments and fit only investors (Kozlovskyi et al., 2020) who accepts price swings and risk of losing everything.

Multinational company "PWC" conducted a survey to find out which cryptocurrency was the most popular in $2021.56 \%$ of responders reported that half of their daily cryptocurrency trading volume is Bitcoin. Top traded altcoins by daily volume are Ethereum (67\%), Litecoin (34\%), Chainlink (30\%), Polkadot (28\%) and Aave (27\%). In this survey any predictions are not made but respondents' price expectations in future are reported (3rd Annual Global Crypto Hedge Fund Report, 2021).

The investment period is also important for cryptocurrency investors. There are much fewer publications devoted to the investment horizon.

In PWC survey (3rd Annual Global Crypto Hedge Fund Report, 2021) four types of investors are presented. There are funds which are long only and whose investors have a longer investment horizon (20\%), funds which cover a broad range of strategies including long and short investing periods (29\%), funds taking a quantitative approach to the market typically have the shortest periods for investors (39\%), multi-strategy funds adopting a combination of the long/short and short periods (12\%).

A large database of statistical data has been collected on the results of daily cryptocurrency trading. Many researchers use these big data for statistical analysis and forecasting the value of cryptocurrencies. In the paper (Liew et al., 2019; Plastun et al., 2019) authors examine the largest 100 cryptocurrency returns ranging from 2015 to early 2018 . One of the results that short-term predictability is very tenuous, which suggests that near-term cryptocurrency markets are semi-strong form efficient and therefore, day trading cryptocurrencies may be very challenging.

In the paper (Chen et al., 2019) was evaluated the comovement between traditional asset classes and the cryptocurrency index by studying their correlation coefficients. Results suggest a very low correlation between cryptocurrency index and traditional assets. So cryptocurrency as an asset class is a good diversifier in a traditional portfolio. Sovbetov (2018) in his paper examined factors that influence prices of most common cryptocurrencies during 8 years from 2010 to 2018. It was proved that attractiveness of cryptocurrencies matters in terms of their price determination only in long-run.

There are a few papers where methods of crypto portfolio are analyzed. Most of them are popular and contains tips for beginners (Coinbase Pro, 2020; BlockSocial, 2021, ForbesAdvviser, 2021 ) and some of them results that it is no need to diversify crypto portfolio (Kenny, 2018). As it can be seen from literature review some publications devoted to which cryptocurrency is better to invest in give descriptive statistics, others form conclusions or report the formed conclusions. More focus is on the short time investing periods, because for investors it is easier to predict the cryptocurrency behavior in the short time period than in the long time period. Taking into account the cryptocurrency big data it is possible to compare and assess the different cryptocurrencies investment efficiency on the different time periods using statistical methods.

\section{METHODOLOGY}

A most popular and powerful statistical method is regression analysis (Kozlovskyi et al., 2021) that allows to examine the relationship between two or more variables. To compare and assess the different cryptocurrencies investment efficiency is useful to examine the influence of different cryptocurrencies on each other. Its result allows concluding whether it makes sense to construct portfolios of cryptocurrencies to maximize expected return. For further research it is proposed to take 3 types of crypto currency. There are Bitcoin, Ethereum, and Litecoin. According to the "PWC" survey these three cryptocurrencies has been the most popular in first quarter of the 2021 (3rd Annual Global Crypto Hedge Fund Report, 
2021). For today Bitcoin stays the most popular cryptocurrency. The first Bitcoin alternative is Ethereum. Ethereum is second most popular and capitalized in the world after Bitcoin. The goal of Ethereum creation is provide anyone in the world by decentralized suite of financial product. The cheaper analogue of Bitcoin is Litecoin. It is called "silver to Bitcoin's gold".

Periods of cryptocurrencies investing depends on strategy. Experts recommend to choose long time horizons and even to invest in a retirement saving plan (Goodman, 2019). Market traders experience the situation when cryptocurrency may fluctuates rapidly by the day. For investors, who prefer long-term strategy period of invest horizon is from a few months to some years. A "one day traders" who invest every week earns a higher profit but have more risks. Usually they do not invest on period more than a month (Derousseau, 2019). From here it is proposed to take long time period equal to 100 days and short time periods equal to 20 days. To make comparative assessment of the Bitcoin, Ethereum, and Litecoin investment efficiency on 20 days time period and 100 days time period the method of regression analysis is going to be used.

The first step is to determine how closely three pairs of variables move in tandem with each other. The first pair is Bitcoin and Ethereum. There are some crucial distinctions between them. These cryptocurrencies have differences in block time, algorithms that they run on and their overall aims. The second pair is Bitcoin and Litecoin. The correlation between these cryptocurrencies is obvious from the technology is used (Stock Correleation, 2020). The third pair is Ethereum and Litecoin. The absolute value of the correlation coefficient of the two variables is correlation coefficient. The correlation coefficient has a value between +1 and -1 . A correlation coefficient of +1 indicates that the variables move in perfect tandem and in the same direction (Frost, 2020).

Then it is necessary to test significance of the model as a whole. One of indicate is the $F$ value. The less the significance $F$, the less probability that model is wrong. It is enough that significance $F$ is less than 0.05. The significance of the coefficient is verified on the basis of Student's t-criterion. The larger the Student's t-criterion, the more reliable coefficient is. To be sure that coefficient is significance it is compared with t-critical value for 95\% confidence interval and 19 degrees of freedom (Frost, 2020).

\section{RESULTS}

For the comparison and assessment of the cryptocurrency is better to invest were used information from the web site "Statista". Its platform contains data about price comparison of 100 cryptocurrencies. 4 samples of 20 observations for each year from 2018 to 2021 were randomly generated from the web site "Statista" big data array. The first sample contains data from June 15, 2021 to June 28, 2021. The second sample contains data from November 12, 2020 to December 1, 2020. The third sample contains data from November 26, 2019 to December 15, 2019. The fourth sample contains data from September 6, 2018 to September 25, 2018. The obtained samples are presented on figure 2.

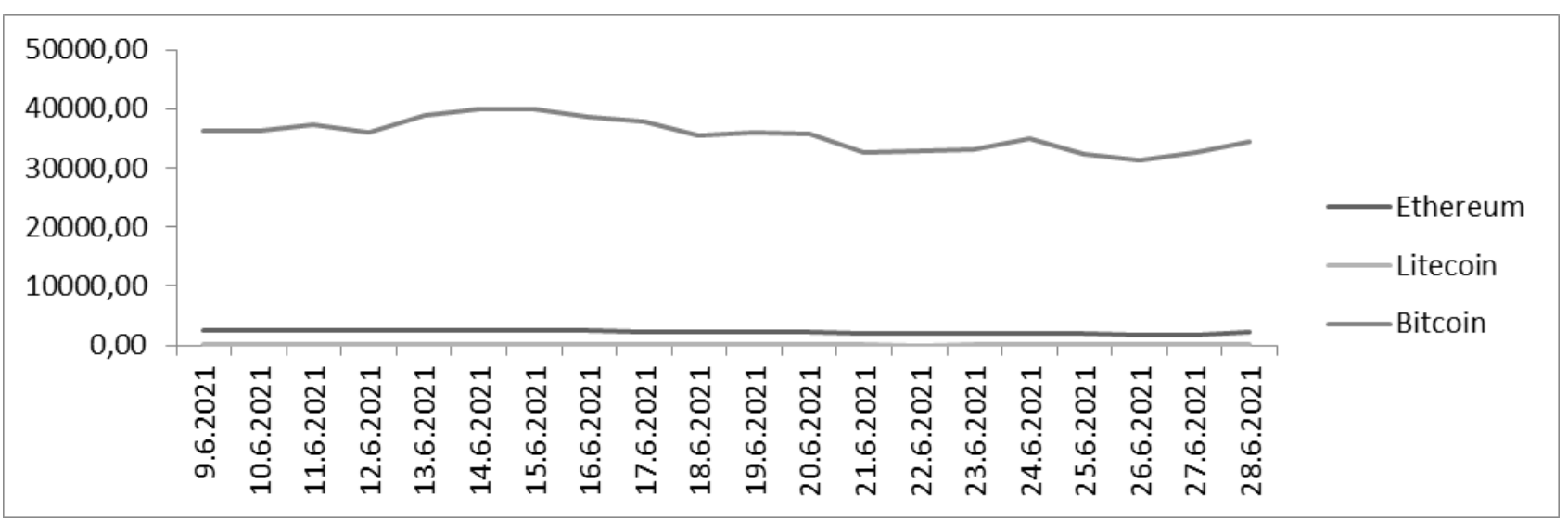



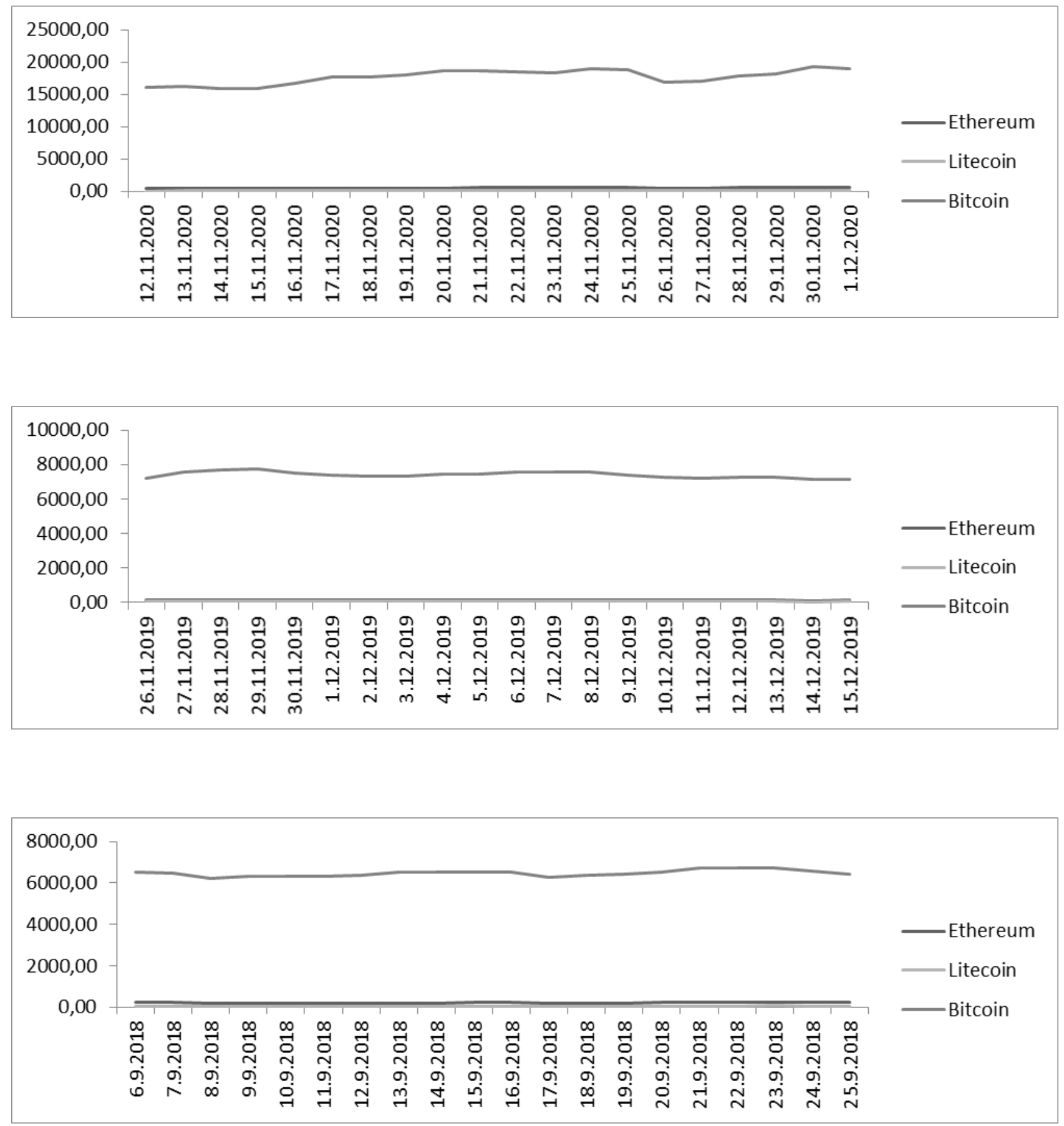

Figure 2. Cryptocurrency value in US dollars on short time periods, 4 samples of 20 observations

Source: developed by the authors

As it can be seen from fig. 2, there is no correlation between Bitcoin, Litecoin, and Ethereum. If to zoom in or leave Litecoin and Ethereum for comparison, then there is no visible correlation either. However, the principle of cryptocurrency mining suggests that the correlation should be. To check it the Regression data analysis tool in Excel was used. The result is shown in Table 1. 
Table 1. The regression analysis result for cryptocurrency value interconnection on short time periods

\begin{tabular}{|c|c|c|c|c|c|c|}
\hline & \multicolumn{3}{|c|}{ Sample 1} & \multicolumn{3}{|c|}{ Sample 2} \\
\hline & ETH / Bitcoin & LTC / Bitcoin & $E T H / L T C$ & ETH / Bitcoin & LTC / Bitcoin & $E T H / L T C$ \\
\hline Multiple R & 0,922 & 0,934 & 0,977 & 0,856 & 0,964 & 0,83 \\
\hline Significance F & $7,78^{-9}$ & $1,85^{-9}$ & $1,72^{-13}$ & $1,48^{-6}$ & $8,2^{-12}$ & $5,86^{-6}$ \\
\hline \multirow[t]{3}{*}{ t-statistics } & 10,08 & 11,37 & 19,33 & 7,025 & 15,41 & 6,32 \\
\hline & \multicolumn{3}{|c|}{ Sample 3} & \multicolumn{3}{|c|}{ Sample 4} \\
\hline & ETH / Bitcoin & LTC / Bitcoin & $E T H / L T C$ & ETH / Bitcoin & LTC / Bitcoin & $E T H / L T C$ \\
\hline $\begin{array}{l}\text { Multiple R } \\
\text { M }\end{array}$ & 0,91 & 0,747 & 0,924 & 0,9191 & 0,912 & 0,951 \\
\hline Significance F & $2,56^{-8}$ & 0,0001 & $6,05^{-9}$ & $1,72^{-8}$ & $2,16^{-8}$ & $1,22^{-10}$ \\
\hline t-statistics & 9,33 & 4,766 & 10,25 & 9,901 & 9,436 & 13,09 \\
\hline
\end{tabular}

Source: developed by the authors

The multiple $\mathrm{R}$ for 4 randomly generated samples indicates that there is strong correlation between Bitcoin and Ethereum, Bitcoin and Litecoin, and Ethereum and Litecoin. The regression result for cryptocurrency value on short time periods indicates that $85 \%-92 \%$ of variation in Litecoin value is explained by Bitcoin value, $74 \%-96 \%$ of variation in Ethereum value is explained by Bitcoin value. And $4 \%-26 \%$ of the variation in Ethereum and Litecoin values is caused by factors other than Bitcoin value. As a consequence, the correlation between Ethereum and Litecoin is in diapason from $83 \%$ to $97 \%$.

As it can be seen from table 1 , the Significance $F$ is very small for each sample. It means that the regression model is statistically significant. The t-statistics for each sample are bigger than t-critical value for $95 \%$ confidence interval and 19 degrees of freedom (t-critical value is 2,093 ). It can be concluded that cryptocurrency value is interconnected on short time periods.

To check the cryptocurrency value interconnection on long time periods is used the same sequence of steps. The data is downloaded randomly from the web site "Statista". The first sample contains data from January 01, 2021 to April 04, 2021. The second sample contains data from June 03, 2020 to September 10, 2020. The third sample contains data from January 05, 2019 to April 14, 2019. The fourth sample contains data from September 23, 2018 to December 31, 2018. The obtained samples are presented on figure 3.

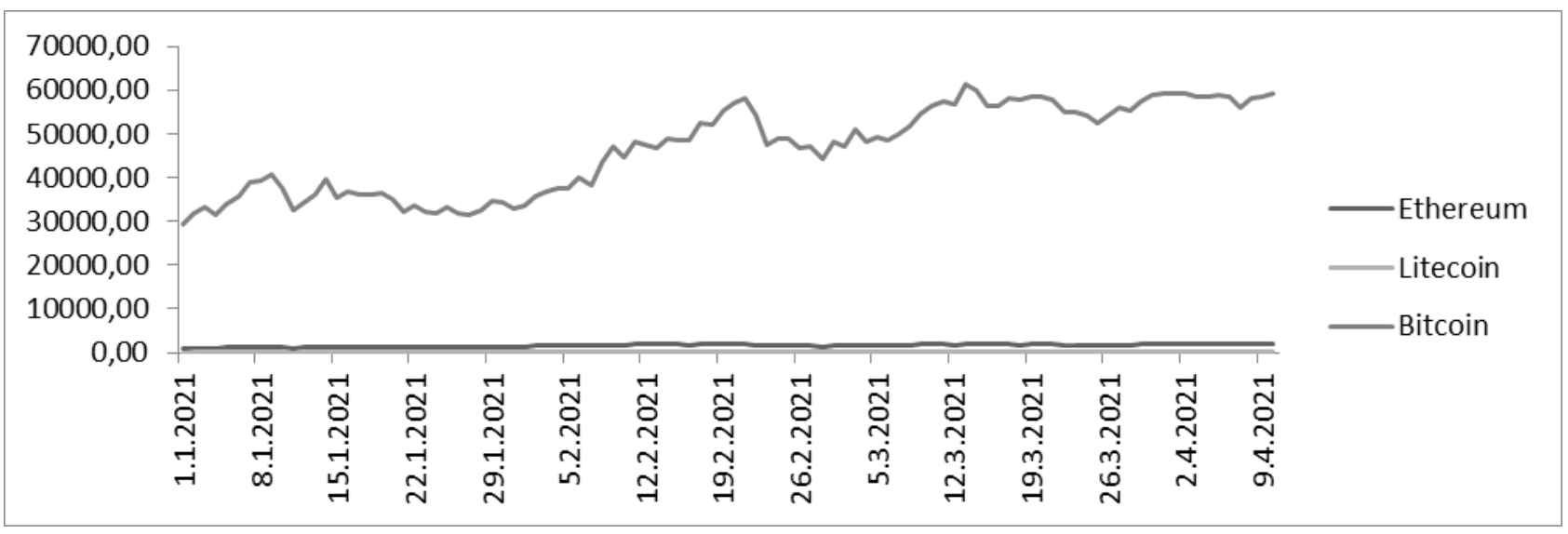



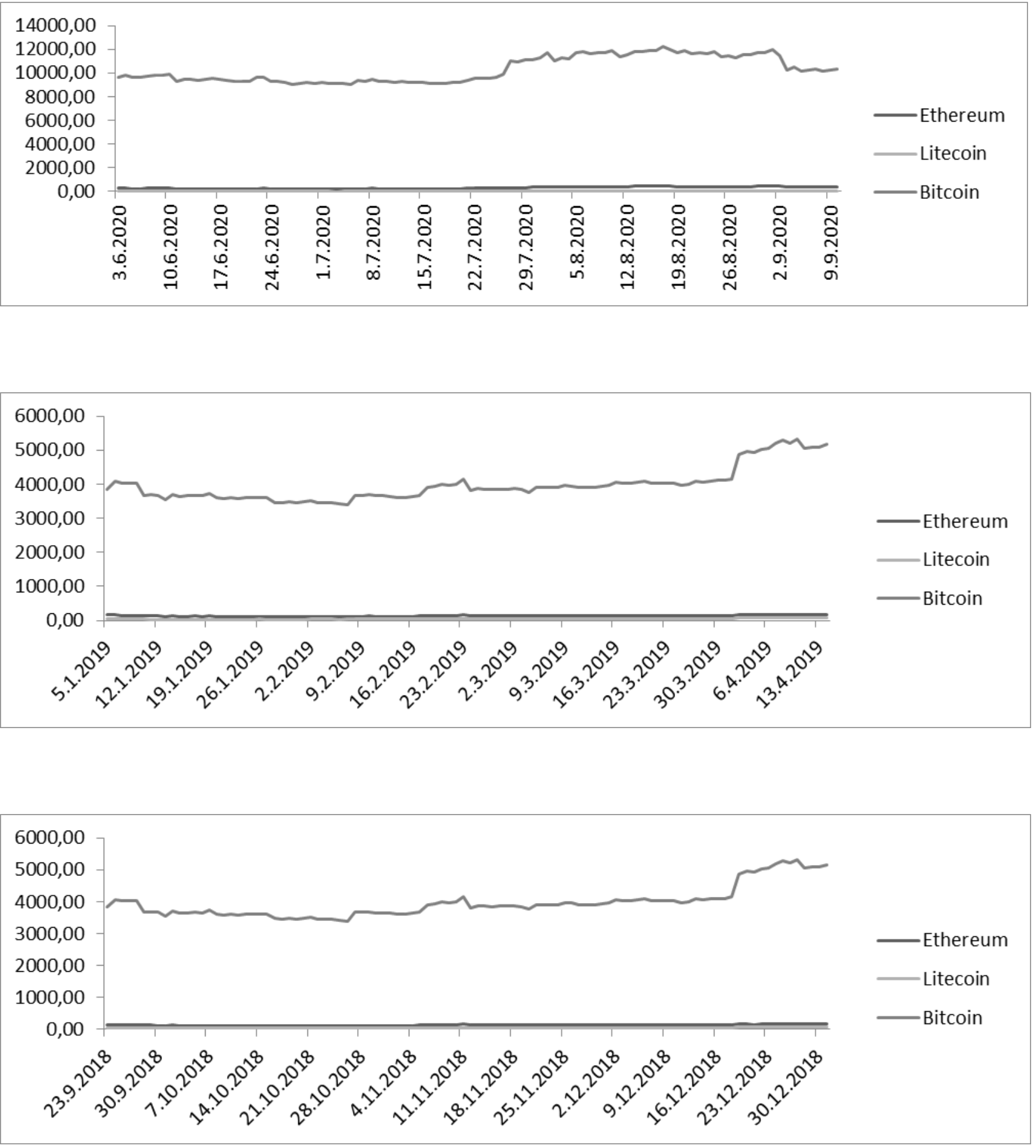

Figure 3. Cryptocurrency value in US dollars on long time periods, 4 samples of 100 observations

Source: developed by the authors

The graph on the fig. 3 shows that over the 100-days period Bitcoin value has been changed more rapidly that Ethereum and Litecoin. Despite the difference in scale in the value of the Bitcoin and Ethereum, Bitcoin and Litecoin, it can be seen that the Ethereum and Litecoin follows Bitcoin. However, the strength of their correlation remains unclear. Also the Regression data analysis tool in Excel was used to check the correlation. The result is in Table 2. 
Table 2. The regression analysis result for cryptocurrency value interconnection on long time periods

\begin{tabular}{|c|c|c|c|c|c|c|}
\hline & \multicolumn{3}{|c|}{ Sample 1} & \multicolumn{3}{|c|}{ Sample 2} \\
\hline & $\begin{array}{l}\text { ETH / } \\
\text { Bitcoin }\end{array}$ & $\begin{array}{l}\text { LTC / } \\
\text { Bitcoin }\end{array}$ & $E T H / L T C$ & $\begin{array}{l}\text { ETH / } \\
\text { Bitcoin }\end{array}$ & $\begin{array}{l}\text { LTC / } \\
\text { Bitcoin }\end{array}$ & $E T H / L T C$ \\
\hline Multiple R & 0,8743 & 0,8987 & 0,852 & 0,9557 & 0,9807 & 0,932 \\
\hline Significance F & $1,53^{-32}$ & $7,2^{-32}$ & $2,67-29$ & $7,17-54$ & $2,72^{-71}$ & $5,46^{-45}$ \\
\hline \multirow[t]{3}{*}{ t-statistics } & 17,839 & 20,293 & 16,112 & 32,156 & 49,672 & 25,458 \\
\hline & \multicolumn{3}{|c|}{ Sample 3} & \multicolumn{3}{|c|}{ Sample 4} \\
\hline & $\begin{array}{c}\text { ETH / } \\
\text { Bitcoin }\end{array}$ & $\begin{array}{l}\text { LTC / } \\
\text { Bitcoin }\end{array}$ & $E T H / L T C$ & $\begin{array}{l}\text { ETH / } \\
\text { Bitcoin }\end{array}$ & $\begin{array}{l}\text { LTC / } \\
\text { Bitcoin }\end{array}$ & $E T H / L T C$ \\
\hline Multiple R & 0,9152 & 0,9259 & 0,836 & 0,9818 & 0,9803 & 0,9866 \\
\hline Significance $F$ & $1,82^{-40}$ & $3,09-43$ & $2,39-27$ & $1,33^{-72}$ & $8,24^{-71}$ & $4,94^{-79}$ \\
\hline t-statistics & 22,482 & 24,274 & 15,112 & 51,287 & 49,092 & 59,938 \\
\hline
\end{tabular}

Source: developed by the authors

As well as for short periods, the multiple $\mathrm{R}$ indicates that the correlation is very high between Bitcoin and Ethereum, Bitcoin and Litecoin, and Ethereum and Litecoin. On long time periods multiple R shows that $87 \%-98 \%$ of variation in Litecoin value is explained by Bitcoin value, $89 \%-98 \%$ of variation in Ethereum value is explained by Bitcoin value. And $2 \%-13 \%$ of the variation in Ethereum and Litecoin values is caused by factors other than Bitcoin value. It is less than for the cryptocurrency value interconnection in the short time period. The correlation between Ethereum and Litecoin in the long time period is approximately the same as in the short time period.

The Significance $F$ is extremely small for each sample. So the regression model is statistically significant and reliable. The t-statistics for each sample are much bigger than t-critical value for $95 \%$ confidence interval.

As it can be concluded from the regression analysis result for cryptocurrency value interconnection on long time periods (table 2), the correlation between Bitcoin and Ethereum, Bitcoin and Litecoin is extremely high as well as the model significance. The correlation between Bitcoin and Ethereum, Bitcoin and Litecoin is higher on the long time periods than on the short time periods.

\section{DISCUSSION}

On the one hand, as it was highlightened in the literature review similar calculation has been carried out (Coinbase Pro, 2020; Kenny, 2018). In it correlation was done for a long investment time periods. During long term correlation may not be truth because of influence of a lot of factors such as cost of mining process, regulation governing and others (Gonzálvez-Gallego and Pérez-Cárceles, 2021). That's why in this paper comparative assessment of the different crypto-currencies investment efficiency was based on periods generated randomly. On the other hand, it can be argued that obtained results show the past pattern. But this pattern can be used up to the moment the mining process or its regulation would not be changed dramatically. The mission of this paper is not only do the regression and find out cryptocurrency value interconnection on the different time periods but also to demonstrate simple and powerful statistical method to make right investment decision in an oversupply of the information. 


\section{CONCLUSION}

Comparative assessment of the investment efficiency between Bitcoin and Ethereum, Bitcoin and Litecoin, and Ethereum and Litecoin on the different time periods by the method of regression analysis allows making such conclusion: Both Ethereum and Litecoin values follow the Bitcoin value. The technology, cryptographic algorithm and other factors do not play the role for its value.

Values of altcoins is also interconnected, but to a lesser extent than with Bitcoin. The described advantages of cryptocurrencies for the investors are mostly the marketing ploy of their creators. On long time periods correlation between Bitcoin and Ethereum, Bitcoin and Litecoin, and Ethereum and Litecoin are higher than on short time periods. On long time periods the investor does not care what currency to invest in to obtain profitability. With a strong correlation between values of cryptocurrencies investor does not need to construct crypto portfolio based on its profitability. An effective strategy is to invest money for long time periods in any cryptocurrencies whose utilities meet the investor's requirements.

\section{REFERENCES}

Bitcoin in Numbers by BlockSocial (2021), Your Guide to Understanding and Capitalizing on a Decentralized World, https://www.blocksocial.com/articles/Bitcoin-in-numbers/

Bryant, P. (2020), Crypto Profit: Your Expert Guide to Financial Freedom through Cryptocurrency Investing, Cryptoprof Publications.

Chen, S., Chen, C.Y.H., Härdle, W.K., Lee, T.M., Ong, B. (2016), A First Econometric Analysis of the CRIX Family, Working paper, http://crix.hu-berlin.de/data/ SFB649DP2016-031.pdf.

CoinDesk Research report (2021), Website CoinDesk, https://www.coindesk.com/research/reports/ investor-perspective-on-btc-taproot-upgrade

Derousseau, R. (2019), The Everything Guide to Investing in Cryptocurrency: From Bitcoin to Ripple, the Safe and Secure Way to Buy, Trade, and Mine Digital Currencies, Adams Media, Avon.

Frost, J. (2020), Regression Analysis: An Intuitive Guide for Using and Interpreting Linear Models, Statistics By Jim Publishing. 355 p.

Gonzálvez-Gallego, N., Pérez-Cárceles, M.C. (2021). "Does goodness of governance dissuade citizens from using cryptocurrencies?". Economics and Sociology, Vol. 14, No. 1, pp. 11-27. doi:10.14254/ 2071-789X.2021/14-1/1

Goodman, G. (2019), How anyone can make money trading Bitcoin and other cryptocurrencies, Harriman Hous. Petersfield.

Hussain, H.I. et al. (2020), "Impact of Country's Governance Dimensions on Bank Revenue Efficiency: Overview on Middle East, Southeast Asia, and South Asia Countries", Transformations in Business \& Economics, Vol. 19, No. 1 (49), pp. 191-228.

Kenny, L. (2018), You Don't Need a Diversified Crypto Portfolio to Spread Risk: Here's Why towards data science, Towards Data Science, https://towardsdatascience.com/bitcoin-dominance-5a95f0f3319e

Kozlovskyi, A., Bilenko, D., Kozlovskyi, S., Lavrov, R., Skydan, O., Ivanyuta, N. (2020), "Determination of the risk-free rate of return on an investment efficiency based on the fractal markets hypothesis", Forum Scientiae Oeconomia, Vol. 8, No. 3, pp. 61-72.

Kozlovskyi, S., Bilenko, D., Dluhopolskyi, O., Vitvitskyi, S., Bondarenko, O., Korniichuk, O. (2021), "Determinants of COVID-19 Death Rate in Europe: Empirical Analysis", Problems of sustainable development, Vol. 16, No. 1, pp. 17-28.

Liew, J., Li, R., Budavári, T., Sharma, A. (2019), "Cryptocurrency Investing Examined", The Journal of British Blockchain Association, Vol. 2, No. 2, pp. 1-12.

Limba, T., Driaunys, K., Stankevicius, A., Andrulevicius, A. (2020), "Cryptocurrency and National Security: Peculiarities of Interaction”, Transformations in Business \& Economics, Vol. 19, No. 2 (50), pp. 138158.

Making sense of Bitcoin, cryptocurrency and blockchain (2018), Report by PWC, https://techjury.net/ blog/cryptocurrency-statistics/\#gref

Plastun, A., Kozmenko, S., Plastun V., Filatova, H. (2019). „Market anomalies and data persistence: The case of the day-of-the-week effect". Journal of International Studies, Vol. 12, No. 3, pp. 122-130. doi:10.14254/2071-8330.2019/12-3/10 
Popper, N. (2016), Digital Gold: Bitcoin and the Inside Story of the Misfits and Millionaires Trying to Reinvent, Harper Paperbacks, New York.

Sovbetov, Y. (2018), „Factors Influencing Cryptocurrency Prices: Evidence from Bitcoin, Ethereum, Dash, Litcoin, and Monero“, Journal of Economics and Financial Analysis, Vol. 2, No. 2, pp. 1-27.

Statista (2021), Big Data Web-site, https://www.statista.com/statistics/655492/most-valuable-virtualcurrencies-globally/

Stock Correleation (2020), Portfolio optimization platform Macroaxis, https://www.macroaxis.com/ invest/pair-correlation/BTC.CC/LTC.CC/Bitcoin-vs-Litecoin

Top 10 Cryptocurrencies In June 2021 (2021), Forbes Adviser, https://www.forbes.com/advisor/ investing/top-10-cryptocurrencies/

3rd Annual Global Crypto Hedge Fund Report 2021 (2021), Report by PWC, https://www.pwc.com/ gx/en/financial-services/pdf/3rd-annual-pwc-elwood-aima-crypto-hedge-fund-report-(may-2021).pdf

When is the best time to invest in crypto? (2020), Coinbase Pro, https://www.coinbase.com/ru/learn/ tips-and-tutorials/dollar-cost-averaging 